\title{
¿Es posible un sainete socialista? Algunas reflexiones en torno a la figura de Pedro E. Pico, socialista y hombre del teatro comercial
}

\author{
Is a socialist sainete possible? \\ Reflections regarding life and work of Pedro E. Pico, \\ commercial playwright and socialist
}

\author{
Javier Guiamet \\ Instituto de Investigaciones en Humanidades y Ciencias Sociales \\ Universidad Nacional de La Plata \\ javierguiamet@hotmail.com
}

(Argentina)

\section{Resumen}

Este artículo aborda la vida y obra de Pedro E. Pico, miembro del Partido Socialista argentino, pero también, importante autor de la escena del teatro comercial en la primera mitad del siglo XX. Al realizar este análisis se pretende discutir los vínculos entre cultura de izquierda y cultura de masas y, a su vez, el modo en que los vínculos entre ambas esferas han sido caracterizados por un espectro amplio de la historiografía consagrada al tema.

El hecho de que estas dos vertientes de su actividad no resultaron contradictorias en su trayectoria obliga a formular nuevas preguntas sobre las interrelaciones entre diferentes lógicas de prácticas culturales y el mundo del entretenimiento en la Argentina de la primera mitad del siglo XX.

Palabras Clave: Pedro E. Pico, partido Socialista, cultura de izquierda, cultura de masas. 


\begin{abstract}
Abtract
This article analyzes Pedro E. Pico's life and work. Pico was a member of the Argentine Socialist Party, as well as an important author of commercial theatre in the first half of the twentieth century. In doing so, the main goal is to discuss the ties between left culture and mass culture, and the way these ties have been characterized by a broad spectrum of the literature devoted to the subject.

The fact that these two sides of his activity were not found as contradictory for him in his carrer brings up new questions to examine the linkage between cultural practices and entertainment in the early half of the twentieth century in Argentina.
\end{abstract}

Keywords: Pedro E. Pico, Socialist party, left culture, mass culture.

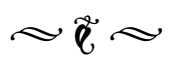

\section{Introducción}

El 4 de octubre de 1914 Pedro E. Pico fue elegido, junto a Spongia Friderich, concejal por la ciudad de Santa Rosa, La Pampa, con 213 votos. Había llegado a aquella ciudad apenas dos años antes para practicar la abogacía, y en ese breve tiempo, impulsó la fundación del Centro Socialista de la región. A su vez, se contaba entre los fundadores del periódico partidario Germinal, cuyo primer número vio la luz un mes antes de las elecciones municipales. Junto a Friderich, Pico asumió su banca con un programa destinado a transparentar la gestión municipal, dentro de un proyecto más amplio del socialismo pampeano cuyo objetivo era "elevar" a la población del territorio a través de las iniciativas educativas y actividades culturales que resultaban características del socialismo argentino. ${ }^{1}$

Llamativamente y apenas unos meses antes, ese mismo año se estrenó La solterona, una co-

1. Véase Martocci (2015). media breve escrita por el mismo Pico, a cargo de la Compañía Pagano-Casaux en el teatro Apolo. Si bien el socialismo argentino reivindicaba al teatro como expresión pura de arte e instrumento para la "elevación material y moral del pueblo" y de allí que no sorprendiera encontrar entre las filas socialistas autores de obras destinadas a las actividades partidarias, La Solterona lejos estaba de pertenecer a los géneros englobados en esta prédica.

E1 formato de comedia breve de la obra se enmarcaba dentro de lo que se conoció en la época como teatro de género chico, el cual reunía sainetes, vodeviles, pochades, comedias, zarzuelas y diversas piezas de diversión de origen popular, cuya brevedad se contraponía a la extensión de las obras clásicas del teatro occidental. ${ }^{2}$ Esta brevedad y diversidad de géneros permitió organizar una oferta teatral conocida como "Teatro por secciones" que volvió sumamente redituable la propuesta de entretenimiento urbano en torno a las salas de

2. Véase Sarli (2013). 
teatro comercial que proliferaban, sobre todo en la ciudad de Buenos Aires. ${ }^{3}$

A pesar de la afición de los socialistas argentinos por el arte dramático, este circuito teatral, que, sobre todo en la década de 1920, tuvo un rol protagónico en la conformación de un mercado de ofertas para el ocio, era profundamente denostado en tanto se lo consideraba parte de las prácticas que contribuían al "embrutecimiento de las masas populares". Esto no impidió, sin embargo, que Pico pudiese alternar entre ambos mundos con total naturalidad. Si el año 1914 representó su debut en un cargo político, no significaba el comienzo de su trayectoria como autor teatral, la cual se había iniciado en 1901 con el sainete La polca del espiante y no había dejado de sumar estrenos todos los años desde entonces, y siempre en salas y con compañías exitosas del teatro comercial.

Este carácter bifronte de Pico parece desafiar la efectividad de ciertos discursos rígidos de los actores de la época que señalaron como absolutamente antagónicas y delimitadas las esferas de la cultura de izquierda y el mercado de entretenimiento destinado al tiempo de ocio. De igual modo, permite matizar las reconstrucciones de cierta historiografía que, posiblemente un tanto vinculada a la misma lógica de los discursos de la época, reprodujo el imaginario de una barrera infranqueable entre los proyectos de instrucción popular, ampliamente difundidos en las primeras décadas del siglo XX y la conformación de una oferta de espectáculos variados cuyo objetivo primordial era lucrativo.

La figura de Pico como autor teatral del género chico y dirigente socialista nos ofrece la

3. Véase González Velasco (2012). oportunidad de repensar las dinámicas de circulación entre distintos ámbitos de la cultura y política argentina en momentos de profundas transformaciones en ambas esferas. Es por ello que, este trabajo se propone repasar su trayectoria para observar de qué modo el análisis de las prácticas concretas tiene la capacidad de tensionar los discursos y las reconstrucciones posteriores de la época.

Como señalamos previamente, la trayectoria de Pico podría insertarse en el cruce de dos coordenadas importantes de la historia argentina de las primeras décadas del siglo XX. Por un lado, el proceso de ampliación democrática que siguió a la sanción de la Ley Sáenz Peña en 1912 y las posibilidades de crecimiento que este proceso otorgó al Partido Socialista hasta la irrupción del Peronismo. Por el otro, su carácter de dramaturgo profesional fue posible en el marco de la conformación de un mercado de ofertas culturales que tuvo en el teatro de género chico un exponente fundamental, al menos, hasta la década de $1930 .{ }^{4}$

Repensar ambos procesos de modo relacional se vuelve fundamental en tanto el socialismo otorgaba gran centralidad a sus prácticas culturales. Estas constituían la herramienta fundamental para lograr la "elevación moral y material del pueblo", objetivo de máxima de la práctica partidaria, pero, a la vez, jugaban un papel clave en las tareas de proselitismo que se ponían en marcha ante cada campaña electoral. De esta manera los socialistas impulsaron todo tipo de instituciones e iniciativas culturales y educativas, siendo esa una de las caras más visibles de su inserción en la sociedad argentina. ${ }^{5}$

4. Véase Guiamet (2017).

5. Véase Barrancos (1991). 
De esta importancia otorgada a la cultura dentro del proyecto socialista se desprende entonces una pregunta por el modo en que estas prácticas se relacionaron con las expresiones predominantes del mundo del entretenimiento que, en estos años, se conformaron en torno a una incipiente cultura de masas. Si el socialismo buscó articular diferentes grupos sociales a través de sus políticas culturales, ¿qué reacciones tuvieron entonces ante un fenómeno novedoso que ganaba fuertemente la atención de un conjunto importante de la sociedad? ¿Se aisló el Partido en sus principios, aunque los mismos los pudiesen alejar de los trabajadores y demás sectores subalternos?

Si bien estos interrogantes podrían dar lugar a un conjunto variado y complejo de respuestas, en la historiografía ha resultado más frecuente pensar en el aislamiento como postura predominante ante esta problemática. A partir de las impugnaciones del revisionismo de la Izquierda Nacional que señaló al socialismo como una fuerza completamente ajena a los "verdaderos" gustos populares, ${ }^{6}$ se instaló la visión del Partido Socialista como una organización política rígida en sus principios y por ende impoluta frente a la contaminación de los espectáculos que no conllevaban como signo distintivo la marca del esclarecimiento popular.

Esta caracterización se reprodujo en autores de los más variados. Es el caso de trabajos como los de Romero y Gutiérrez (2007) sobre la sociabilidad en las bibliotecas populares en los años de entreguerras. Allí, el carácter iluminista de las iniciativas de instrucción para los vecinos, de las que el socialismo participaba activamente, no habría tenido en las ofertas de la cultura de masas más que un competidor

6. Véase Correa-Fiebelkorn (2018). antagónico por la atención de los sectores populares. Del mismo modo, Osvaldo Graciano (2008) en su trabajo sobre intelectuales de izquierda para el mismo período, al referirse a las prácticas culturales del socialismo, afirma que en su intención por disponer del tiempo libre de los trabajadores tuvieron que competir con "la creciente gravitación que en su vida cotidiana ejercían el fútbol, el boxeo, la radio, el cine y el periodismo"(p. 218).

Esta caracterización pareciera haberse replicado, a su vez, en la historiografía de izquierda más reciente. Así podemos ver cómo Hernán Camarero (2007) postula para las décadas de 1910 y 1920 la existencia de una cultura obrera -dentro de la que incluye las iniciativas del PSclaramente delimitada de las formas del "ocio alienado" que, según el autor, no alcanzarían total hegemonía en la cultura argentina hasta entrados los años "treinta". De esta manera, vemos que la descripción de ambos fenómenos como compartimentos estancos, que ya había estado presente en las reconstrucciones de los dirigentes socialistas, se reprodujo luego en un arco muy amplio de la historiografía como una suerte de consenso que evito preguntarse por las posibles influencias, intercambios o desafíos que las nuevas formas de la cultura presentaban al mundo de la política dado el nuevo marco en el que ésta se desarrollaba a partir de la Ley Sáenz Peña.

Si bien la trayectoria de una persona no alcanza para desarmar una caracterización de esta índole, la polivalencia de Pedro E. Pico permite introducir un matiz en estos discursos y abrir una puerta para pensar intercambios más fluidos o, al menos, fronteras más porosas. No se trata entonces de negar las características predominantes de la cultura socialista, pero sí de discutir y repensar la existencia de vasos co- 
municantes con otras formas de la cultura, así como una existencia mucho mayor de zonas grises que escapan a la pretensión de absoluta coherencia de los actores históricos y sus postulados.

\section{Actividad política $y$ teatro social en la trayectoria de Pedro E. Pico}

Pedro Eugenio Pico nació en Buenos Aires en 1882 donde asistió al Colegio Nacional antes de estudiar Derecho. ${ }^{7}$ Cuando era joven estrenó en el teatro Apolo su primera obra, $L a$ polca del espiante. Según cuenta el mismo Pi$\mathrm{co}^{8}$ aquel sainete fue llevado a escena por la compañía Podestá, máximo emblema del circo criollo y el teatro popular. En un relato posterior Pico elogiaría con énfasis las actuaciones de los Podestá al tiempo que se jactaría de haberse adelantado a Vaccarezza (el más exitoso autor del género chico) en la presentación de personajes criollos cómicos del interior como el caso de una sirvienta en la obra "santiagueña candonga y charlatana”. De esta manera, Pico inscribía su debut en el teatro dentro de las tradiciones fundamentales de lo que fue el teatro de género chico el cual podía ser vilipendiado por críticos, intelectuales y, también, por socialistas. $^{9}$

Dos años después, en 1903, Pico estrenó su segunda obra ;Para eso se paga! en el Teatro de la

7. Pico, P. (noviembre de 1951). Agua en las manos. En Argentores. Revista Teatral, Año XV (segunda época), No 282. Colección digital, Instituto Ibero-Americano, Berlín.

8. Pico, P. (septiembre de 1934). Yo no se decir no. En Argentores Revista teatral, Año I, No 22.

9. Véase González Velasco (2012); Guiamet (2017).
Comedia. De allí en adelante su carrera como autor no hizo más que crecer. En efecto, estrenó obras prácticamente todos los años, colaboró con distintos autores reconocidos del teatro comercial y hacia los últimos años de su vida su repertorio artístico se completó con varios guiones para cine hasta 1945, año de su fallecimiento.

En relación a su actividad como escritor, justamente, llegarían las primeras participaciones en política con las luchas por los derechos de autor y la integración de sociedades gremiales. No sería, sin embargo, hasta la década de 1910 con su mudanza a la ciudad de Santa Rosa, Territorio Nacional de La Pampa, que viviría su experiencia más importante dentro de la política.

Arribado a Santa Rosa en 1912, participó al año siguiente de una gira realizada por el territorio con Juan B. Justo y Nicolás Repetto. Ese mismo año, a su vez, se erigió como uno de los fundadores del Centro Socialista de esa ciudad, a lo cual siguió la fundación del periódico Germinaly su elección como concejal en 1914, rol en el que se destacaron sus intervenciones a favor de un mayor cuidado para las bibliotecas públicas de la ciudad.

A su vez, la profesión de abogado le permitió, en diferentes casos, defender a presos políticos o litigar a favor de la Liga Agraria. Como ha señalado Federico Martocci (2015), en estos años el socialismo pampeano dio un lugar importante a las problemáticas de los pequeños agricultores dentro de su programa político. En esta línea se destacan dos notas que escribió Pico para La Vanguardia -órgano oficial del Partido Socialista- en 1917 sobre las promesas incumplidas del gobierno nacional en torno a 
la distribución de semillas para pequeños agricultores. ${ }^{10}$

Por fuera de estas particularidades, su actuación política se enmarcó en las habituales coordenadas del socialismo argentino de la primera mitad del siglo XX. El dictado de conferencias y la producción de escritos para el diario partidario fueron parte de las tareas destinadas a elevar a la población pampeana. En tanto La Pampa aún constituía un Territorio Nacional, la menor importancia que tenía allí la política formal hizo que los socialistas se abocaran, sobre todo, a la tarea de instruir a la ciudadanía. Si bien la condición legal del Territorio impedía la formación de instituciones políticas formales en las localidades que no alcanzaban los mil habitantes, Martocci señala que para el socialismo:

La instrucción política no se limitaba al período electoral ni a esa cuestión específica: era una actividad más amplia que debía desarrollarse de manera continua. Esta actitud indica que los socialistas pampeanos manejaban una concepción de ciudadanía que no se limitaba al ejercicio electoral, quizá debido a que, como han planteado otros autores que investigan espacios territorianos, para los trabajadores y demás sectores populares la política en muchos casos discurría por carriles alternativos, que no implicaban necesariamente la participación en los (a veces inexistentes) órganos de gobierno (2015, p.46).

En este caso, la participación de Pico incentivó que el socialismo pampeano otorgara un lugar destacado al teatro dentro de su repertorio de

10. Pico, P. (29 de enero 1917 y 30 de enero 1917).

Distribución de semilla. La Vanguardia, Biblioteca

Popular Francisco Romero Delgado, Universidad Popular Alejandro Korn, La Plata. prácticas culturales (lo mismo en las colecciones editoriales), en muchos casos representando obras de su autoría. Es de destacar que en estas ocasiones las piezas elegidas eran, por lo general, dramas o bocetos dramáticos y, en menor, medida sainetes y comedias breves.

La experiencia política en el incipiente socialismo pampeano influenció una serie de obras destinadas a retratar problemáticas sociales de esa región. En este aspecto Pico fue valorado como un "lúcido captador de estampas vivas extraídas de la realidad y expuestas en un léxico estrictamente teatral, en el cual las pautas de lo popular se iban dando sin cargar las tintas y sin concesiones al costumbrismo y a la chabacanería". ${ }^{11}$ Fue también en la Historia del teatro argentino en las provincias dirigida por Osvaldo Pelletieri (2005) donde se destacó el contenido social de las obras de Pico, destinadas a retratar la vida de sectores marginados o empobrecidos por la marcha de la economía. Federico Martocci (2015) coincide en señalar que uno de los rasgos sobresalientes de este dramaturgo fue su capacidad de representar elementos característicos de la sociedad pampeana desde una perspectiva crítica.

\section{Géneros populares, circuito comercial y recepciones desde el socialismo}

Más allá de las apreciaciones expuestas en el apartado anterior, la producción de Pedro E. Pico no puede reducirse al influjo de su experiencia como dirigente político de un territorio predominantemente rural. Sin embargo, investigaciones posteriores prestaron mayor

11. Palabras del crítico Nervi reproducidas por: Martocci (2015, p. 105). 
atención a esta faceta que a su obra como sainetero y comediógrafo. Pareciera correr aquí la misma suerte que muchos autores populares de los años veinte. González Velasco sostiene que la concepción que ligaba al género chico a una especie de fábrica teatral, donde todas las producciones eran más o menos parecidas, dio como resultado que, a posteriori, los historiadores y críticos despreciaran esta época del teatro argentino, calificándola como un período de cierta decadencia artística, sin arriesgarse a un análisis más profundo (2012, p. 57). Esta reducción simplista, en el caso particular de Pico implicaría perder de vista su rica trayectoria como autor dedicado al entretenimiento.

Una excepción a este vacío es el lugar que le otorga Luis Ordaz en la ya clásica colección de Historia de la literatura argentina, editada por el Centro Editor América Latina. Allí, Ordaz no duda en ubicar a Pico como uno de los comediógrafos más destacados de su tiempo. Haciendo un barrido por toda su trayectoria, que se mantuvo siempre dentro de la producción de obras breves características del género chico, Ordaz destacaba de Pico:

Es muy capaz, por supuesto, de ahondar en el drama, y hasta de efectuar una protesta y una denuncia social, pero su mejor vena y su talento muestran particularmente al comediógrafo sumamente diestro y bien preparado para los desarrollos, con ciertas intencionalidades, de la farsa y la burlería (1980, p. 177).

La combinación de dramas o bocetos dramáticos en un acto, sainetes y comedias breves son la marca de una carrera que reúne en 44 años más de 60 obras. Ni siquiera en los momentos más agitados de militancia en el socialismo pampeano dejó Pico de estrenar sainetes y comedias en los principales teatros de Buenos
Aires. Un ejemplo de este carácter prolífico y polifacético fue $A$ media noche, estrenada en junio de 1917 en el Teatro Nacional, a cargo de la "Compañía de Sainetes, Revistas y Zarzuelas Vittone-Pomar".

La obra en cuestión, con "fondo de tango"12 ejecutado por una orquestilla en un bar reunía, como en un salpicado, diferentes personajes afligidos por la soledad y la angustia de la $\mathrm{mi-}$ shiadura. Con diálogos mal escritos buscando reflejar un lenguaje popular, se sucedían peleas entre mamaos, disputas, intrigas amorosas y mujeres que seducían a figuras masculinas protectoras para librarse de otras.

La fuerte impronta que tenía la temática urbana y sus personajes, el fondo de tango, la búsqueda por reflejar las variedades del lenguaje popular de una ciudad invadida por el cosmopolitismo, eran lugares comunes de las obras del género chico que Pico compartía en sus producciones.

Estas características de $A$ media noche no privaron a $L a$ Vanguardia de afirmar que: "ha constituido uno de los mejores éxitos de la Compañía Vittone-Pomar, y uno de los más legítimos entre la producción nacional" ${ }^{13}$ Sin

12. El tango resultaría uno de los géneros musicales más atacados por el socialismo argentino. A mediados de la década de 1930 se podía leer en Vida Femenina, publicación partidaria, la siguiente frase: “ $¿$ Es posible continuar así? "¿Seguirá el pueblo cantando el tango y aplaudiendo el sainete de mal gusto?”. Storni, R. (1936). Por la cultura del pueblo, Vida Femenina, año 3, n 26 , p. 19.

13. Sin título. (12 de junio de 1917). La Vanguardia. Un dato curioso es que esta obra aparece anunciada en un recuadro que se destaca por su tamaño dentro de la página en la que está, y que aparece además con una fotografía de los actores. La publicidad de una obra resultaba algo muy poco frecuente en estos años en el periódico socialista, pero mucho más inusual era que 
ahondar en las causas de esa mayor legitimidad, La Vanguardia se ocupó por lo general de celebrar las obras de Pico (sin hacer referencia a su filiación partidaria), aunque a veces no fueran más que diferencias sutiles las que pudiera rescatar para diferenciarlo del resto de los autores a los que criticaba duramente.

Con una propuesta estética similar encontramos la comedia No hay burlas con el amor. De ella también La Vanguardia hizo una reseña elogiosa. Señalaba que constituía el primer acierto del año por parte de la reconocida compañía de sainetes, y destacaba no solo el valor de la obra, sino también que no caía en la demagogia de responder a las expectativas de un público acostumbrado a la "deformación absoluta”.

Esto era posible porque "para Pico el sainete se ajusta a un cartabón determinado: el aspecto risueño de los personajes no llega a lo grotesco, la nota sentimental no cae en el linde de lo cursi". ${ }^{14}$ A continuación, la reseña reconstruía brevemente el argumento de la obra, dejando afuera elementos que podrían ser contradictorios con la ideología socialista.

Para La Vanguardia, la historia de Pico se basaba en un enredo amoroso entre una muchacha, Rosina, que enamorada de un "honrado trabajador", al sentirse desairada por éste, terminaba casándose con un comerciante. Cuando el trabajador le confesó su amor, Rosina comenzó un amorío con él a espaldas del comerciante, quien, al enterarse, en vez de reaccionar con

el mismo viniera con una fotografía. Si tenemos en cuenta que Pico en 1917 aún era dirigente del socialismo pampeano es posible suponer que esto haya permitido una mayor facilidad para publicitar su obra a través de $L a$ Vanguardia.

14. Sin título. (10 de abril de 1921). La Vanguardia. enojo, decidió volverse a su tierra natal para permitir que su esposa pudiera encauzar su verdadero amor. Ante este gesto de generosidad, la muchacha se enamoró finalmente del comerciante.

La obra, así resumida, representaba para $L a$ Vanguardia una fábula sobre el amor que se encontraba ajeno a los intereses y las mezquindades. Esta reconstrucción, sin embargo, dejaba afuera elementos cuya reivindicación no resultaban coherentes con la moral socialista. En principio, el comerciante (dueño de un bar $^{15}$ donde sonaba una orquesta de tango a toda hora), usaba a Rosina para atraer a la clientela. La belleza de la muchacha era motivo de disputas entre los clientes. El comerciante, entonces, se ocupaba de alimentar los deseos de esos clientes, diciéndoles a todos, por separado, que sabía de primera mano que el amor de Rosina era para ellos, buscando que siguieran yendo al bar, ilusionados de acercarse a la muchacha en cuestión. Esta estrategia finalizó cuando ocurrió otro evento omitido en la reseña, el comerciante le propuso casamiento a Rosina después de ganar la lotería (es importante recordar que el juego era uno de los elementos de la cultura popular más combatidos por el socialismo), creyendo que su reciente riqueza le otorgaría un privilegio sobre la muchacha.

Cuando el enredo amoroso se acercaba a su desenlace, el comerciante, reivindicando sus emociones por haber ganado la lotería, justificó esa pretensión individual a través de un argumento también de compleja asimilación para el Partido. Allí, sostenía ante Rosina que:

15. Recordar que los bares eran ámbitos criticados por el socialismo en tanto podían ser lugares de acceso al alcohol y al juego. Véase Martocci (2015); Hora (2014). 
Entonces, solo me dominaba un deseo: hacer plata. Esto tú no lo comprendes. Para comprenderlo es necesario haber pasado hambre, nacer en la miseria, no ser nunca chico porque desde chico tienes que ganarte el pan como los hombres; resolverte un día a dejarlo todo: la casa, la aldea, la patria; poner un beso que supones el último entre las arrugas de tu vieja, y meterte en la bodega de un barco enorme, y cruzar el mar, y llegar a una tierra desconocida... ${ }^{16}$

Esta manera de reivindicar la experiencia del pobre no era necesariamente coherente con los postulados socialistas, los cuales sostenían que la mejora individual debía darse en el plano de la conciencia y la cultura, proceso a través del cual se podría transformar la sociedad en su conjunto. Pero sí se enmarcaba dentro de los valores del melodrama de la época (donde la sociedad aparecía dividida dicotómicamente entre el bien y el mal y estos valores eran encarnados por pobres y ricos respectivamente), que, como ha sido señalado por Mathew Karush (2013), se encontraban sumamente extendidos en la producción cultural argentina del período de entreguerras.

Podemos ver, entonces, de qué manera La Vanguardia construía una reivindicación de la obra de Pico basaba en resaltar los fundamentos más afines a las tradiciones del socialismo (por ejemplo, destacar la importancia que tenía en la obra la fábula, frente a otras historias que no contenían un mensaje), dejando afuera los elementos contradictorios que emparentaban a la obra de Pico con el conjunto más amplio de puestas en escena del género chico que eran furor en el teatro nacional.

16. Pico, P. (1921). No hay burlas con el amor. Bambalinas, revista teatral, año IV, 158. Colección digital, Instituto Ibero-Americano, Berlín.
Inclusive, la reseña del periódico socialista podía resultar mucho más halagadora que la de los diarios de mayor tirada nacional -a los cuales los socialistas también acusaban de favorecer el "embrutecimiento popular"- donde no aparecían tantos argumentos para destacar a Pico por encima de otros autores. Así, La Prensa sostenía al respecto del estreno de la obra en cuestión:

El público que acudió al estreno acogió favorablemente la nueva producción del señor Pico. Hay en ella, algunos tipos bien observados y diseñados con trazo firme, escenas pintorescas, un diálogo animado y a veces gracioso, y un asunto, que, aun cuando de escasa originalidad, logra interesar al público por la forma hábil en que está expuesto. ${ }^{17}$

Vemos entonces que, por fuera de la reivindicación de La Vanguardia, Pico era considerado como uno más entre los autores que nutrían de obras a los principales teatros de Buenos Aires, destacando inclusive su escasa originalidad en las temáticas sin que eso desmereciera las virtudes de su pluma.

Una referencia similar puede encontrarse en La Nación donde, ante el estreno de La Seca, calificó a la intriga central del boceto como "una trivial historia de la muchacha seducida y abandonada", ${ }^{18}$ subrayando nuevamente la carencia de novedad y singularidad.

Hacia los años veinte, Pico se inclinó cada vez más a realizar obras en colaboración con otros autores del circuito comercial. Uno de los

17. Sin título. (8 de abril de 1921). La Prensa. Hemeroteca, Biblioteca Pública de la Universidad Nacional de La Plata, La Plata.

18. Sin título. (18 de junio de 1917). La Nación. Hemeroteca, Biblioteca Pública de la Universidad Nacional de La Plata, La Plata. 
dramaturgos con los que colaboró fue Samuel Eichelbaum, quien se definía como "uno de los autores dramáticos que menos cobra en el país." ${ }^{19}$ Pico compartía con Eichelbaum la doble filiación como artista de los géneros populares y adherente al socialismo. Si bien la relación de este último con el socialismo no fue tan estrecha como la de Pico, el autor, hijo de inmigrantes rusos judíos, se reconocía como partidario de la ideología y en la década de 1930 llegó a ponerse al frente de la Agrupación Artística Juan B. Justo como director de arte. ${ }^{20}$ Más allá del parentesco ideológico $\mathrm{y}$ de que realizaron juntos dramas y bocetos dramáticos (siempre dentro del género chico), también colaboraron en comedias y sainetes.

Nuevamente, La Vanguardia se ocupó posteriormente de resaltar las obras escritas por este dúo, aunque muchas veces tuviera que recurrir a diferencias sutiles para justificar su superioridad con respecto a la producción mayoritaria del teatro nacional. Es así que, ante el estreno de Un romance turco, boceto dramático en un acto, estrenado por la compañía Muiño-Alippi, sostuvo que:

Pertenece a la categoría de esas obras que aparecen de tiempo en tiempo, agregando un valor más a lo bueno con que cuenta nuestro teatro. En trozos firmes, en escenas sobrias y coloridas los autores nos presentan un cuadro vívido y real. Un trozo de vida de una colectividad innúmera de la metrópoli y cuya existencia, costumbres y prejuicios no

19. Cuentistas argentinos de hoy. (agosto de 1928).

Revista Claridad, año 7, 165, p. 18. Centro de

Documentación e Investigación de la Cultura de Izquierdas (CeDInCI), Buenos Aires.

20. Goldstein, R. (septiembre de 1933). Agrupación Artística Juan B. Justo. Revista Claridad, Año 12, 269, p. 31 . son conocidos de la mayoría de una población cosmopolita como la nuestra. ${ }^{21}$

Si bien la historia de amor que estructuraba a la obra se desarrollaba en el marco de conflictos religiosos, la temática del enredo amoroso entre dos hombres que se disputaban la misma mujer era una escena harto repetida en las obras contemporáneas, y el tratamiento que hacían Pico y Eichelbaum del tema no era esencialmente diferente de lo que podía encontrarse comúnmente en el teatro argentino.

Aunque no se explicitara, podemos suponer que la intención del socialismo de diferenciarlos del resto de la escena teatral se sostenía tanto por el perfil de estos autores -supuestamente más serios- como también por su mayor cercanía con el socialismo. En la reseña La Vanguardia destacaba que: "A los méritos indiscutibles de la obra va unido el valor de dos firmas prestigiosas: una, la de Pico, que tiene en su haber legítimos y honrosos títulos; la otra, la de Eichelbaum, cuyo talento se ha manifestado en una iniciación brillante” ${ }^{22}$

Hemos elegido hacer mayor hincapié en el análisis de las obras de las décadas de 1910 y 1920 ya que coinciden con los años de la trayectoria de Pico más vinculados a la política. La década de 1910 vinculada directamente a su participación en el socialismo pampeano, y los veinte como compañero de ruta (siguió presentándose en actividades partidarias) y más comprometido con la sociedad de auto-

21. Pico, P. y Eichelbaum S. (agosto de 1920). Un romance turco, La escena. Revista teatral, Año III, p. 3. Colección digital, Instituto Ibero-Americano (IIA), Berlín. (La reseña de La Vanguardia fue recuperada en la edición impresa del guion de la obra por parte de $L a$ escena).

22. Pico, P. y Eichelbaum S. (agosto de 1920). Un romance turco. La Vanguardia. 
res, aunque a partir de aquí ya resulte más difícil reconstruir su relación con la política. Todo lo contrario, a lo que ocurre con su trayectoria artística que siguió creciendo incorporando labores como guionista para radioteatro y para cine, donde participó en más de una decena de películas, completando un perfil más que interesante en torno a las posibilidades que brindaba la cultura de masas en el Río de La Plata.

\section{Conclusiones}

En un trabajo reciente Lila Caimari (2016) señalaba que la idea de una "cultura de mezcla" para describir a Buenos Aires en las primeras décadas del siglo XX se ha convertido en una referencia común dentro de la bibliografía especializada. La caracterización, acuñada originalmente por Beatriz Sarlo a finales de los años ochenta, ha servido para dar cuenta de un estado de la cultura argentina en tensión entre elementos tradicionalistas y los imaginarios de modernidad importados desde los países centrales. Esta mezcla fue condición precisamente de una modernidad que, al situarse en la periferia mundial, se constituyó a partir de la combinación de "modernidad europea y diferencia rioplatense, aceleración y angustia, tradicionalismo y espíritu renovador, criollismo y vanguardia" (Sarlo, 1988, p. 15). Esto ha llevado a la autora a afirmar que: "la densidad semántica del período trama elementos contradictorios que no terminan de unificarse en una línea hegemónica" (1988, p. 28).

Las ideas principales del libro de Sarlo -de los cuales los conceptos "cultura de mezcla" y "modernidad periférica" han resultado los más emblemáticos- tuvieron, a posteriori, una influencia fundamental en las investigaciones sobre el período interesadas en problemáticas relacionadas a lo cultural. Sin embargo, no parecen haber tenido un impacto relevante en los estudios sobre las culturas de izquierda en argentina en los mismos años. Esto es particularmente visible en el caso del estudio de la cultura socialista, salvo contadas excepciones. ${ }^{23}$

La intención de repensar la política en función de los procesos culturales predominantes de la época fue explorada en los últimos años por investigaciones originales que repensaron el modo en que ambas esferas se relacionan en el terreno de lo empírico. Es así que Matthew Karush (2013) llamó la atención sobre las posibilidades de realizar una lectura política de las principales ficciones nacionales para radio y cine en los años veinte y treinta, encontrando en ellas valores y representaciones sobre la sociedad que luego recogería el peronismo.

Más recientemente, Graciela Montaldo (2016) postuló una relectura política de la cultura de masas en la Argentina finisecular en tanto campo de incorporación de las masas que se encontraban excluidas del pacto de ciudadanía. En este sentido destacó:

La cultura de masas, al generar una nueva dinámica de producción y consumo, resignifica y politiza la forma en que la cultura comienza a operar como un campo abierto de inclusiones y exclusiones sociales; es el momento en que la cultura se hace abiertamente política para todos los ciudadanos. (...) La cultura de masas, en su inicio, es un espacio abierto donde las fronteras que separan a los diferentes sectores tienen una relativa porosidad, que genera nuevas formas de intercambios simbólicos y políticos (2016, p. 13).

23. Véase Barrancos (1991); Buonuome (2016). 
Los abordajes de estas investigaciones $y$, sobre todo, las inquietudes que las impulsaron, llevadas al estudio de las posturas y prácticas de izquierda en torno a la cultura podrían ampliar y renovar la mirada que tenemos sobre las mismas. En primer lugar, en el caso que concierne a este trabajo, permitieron repensar a los socialistas como actores dentro de un contexto más amplio donde la incorporación de las masas a través de la cultura aparece como una problemática extendida en la sociedad. Por otro lado, posibilitaron reponer la existencia de vasos comunicantes entre las prácticas socialistas y aquellas provenientes de otras esferas, abriendo la mirada hacia intercambios e influencias más fluidas que las demarcadas por los discursos de la época.

No por ello el caso individual de Pedro Pico resultó suficiente para desechar las caracterizaciones más comunes sobre la cultura socialista y su relación con otras formas de la cultura, pero sí que, en tanto su figura encarnó la supuesta contradicción entre dos mundos, nos ha permitido, al menos, profundizar la pregunta sobre las fronteras que los ligaban.

Si bien la pregunta que titula este trabajo no pareciera haber sido formulada ni por $L a$ Vanguardia al reivindicarlo ni por Pico en sus producciones, la posibilidad de que un dirigente socialista (y luego en los años veinte un compañero de ruta ${ }^{24}$ fuera un destacado autor de los géneros más vilipendiados del teatro comercial abre una puerta para pensar convivencias más flexibles que lo que sugieren los discursos políticos e intelectuales de la época

24. Martocci (2015) hace referencia a la presencia de Pico en distintas actividades partidarias en los años posteriores a su regreso a Buenos Aires. en su intento por demarcar rígidamente la distinción entre arte "verdadero" y "comercial" y, a su vez, el modo en que han sido analizados posteriormente. El elogio de las obras realizado por La Vanguardia muestra que, puestos a hacerlo, los socialistas podían encontrar diferencias dentro de la escena teatral que en otros momentos definían como un bloque casi homogéneo responsable de la decadencia del teatro nacional.

Inclusive, si comparamos los elogios de $L a$ Vanguardia, con el trato más austero que Pico recibía en otros medios, podemos conjeturar que, aún sin explicitarlo, los socialistas no buscaron esconder las zonas grises de la producción de Pico, sino que elogiaron sus dotes como autor teatral por encima de otros autores y en mayor medida que periódicos que no tenían un problema "moral" con respecto a las producciones del género chico.

Aún cuando la mayor presencia de dramas o bocetos dramáticos en las actividades del socialismo pampeano mostró que Pico concebía como de mayor afinidad con la política a sus obras más solemnes, esto no funcionó como un bloque cerrado (esporádicamente comedias $\mathrm{y}$ sainetes fueron parte de espacios vinculados a la política) ni tampoco habilita aseverar que Pico entendiera que las obras destinadas al entretenimiento fueran contradictorias con su práctica política ya que, como dirigente del socialismo pampeano, siguió en esos años estrenando comedias y sainetes en los principales teatros de Buenos Aires.

De esta manera, el caso de Pico ilustra de manera cabal las posibilidades de una "cultura 
de mezcla”, e invita, más que a ser tachado de anomalía, a repensar las características y el desarrollo de una política cultural del socialismo a la luz de las profundas y complejas transformaciones de la cultura de su época.

$$
\propto \ddot{e} \propto
$$

Recibido: 15-11-2018

Aceptado: 03-05-2019

Publicado: 04-12-2019 


\section{Referencias Bibliográficas:}

Barrancos, D. (1991). Educación, cultura y trabajadores (1890-1930). Buenos Aires: CEAL.

Buonuome, J. (2016). Periodismo militante en la era de la información. La Vanguardia, el socialismo y los orígenes de la cultura de masas en la Argentina (1894-1930) (Tesis doctoral inédita). Universidad de San Andrés, Victoria, Argentina.

Caimari, L. (2016). Buenos Aires. Mezclas puras: lunfardo y cultura urbana. En A. Gorelik y A. Peixoto (Comps.). Ciudades sudamericanas como arenas culturales (pp. 154-173). Buenos Aires: Siglo Veintiuno Editores.

Camarero, H. (2007). Consideraciones sobre la historia social de la Argentina urbana en las décadas de 1920 y 1930: clase obrera y sectores populares. Nuevo Topo. Revista de historia y pensamiento critico, 4, 35-60.

Correa, E. y Fiebelkorn, A. (2018). Prolegómenos de una nueva corriente historiográfica: los debates sobre la historia argentina y la tradición socialista en el PSRN y su aporte a la formación de la Izquierda Nacional. Ponencia presentada en Segundas Jornadas Nacionales de Historiografía. Río Cuarto, Argentina.

González Velasco, C. (2012). Gente de teatro. Ocio y espectáculos en la Buenos Aires de los años veinte. Buenos Aires: Siglo veintiuno editores.

Graciano, O. (2008). Entre la torre de marfil y el compromiso politico. Intelectuales de izquierda en la Argentina 1918-1955. Bernal: Universidad Nacional de Quilmes.

Gutiérrez, L. y Romero, L. (2007). Sectores populares, cultura y politica. Buenos Aires en la entreguerra. Buenos Aires: Siglo Veintiuno Editores.

Guiamet, J. (2017). Tentaciones y prevenciones frente a la cultura de masas. Los socialistas argentinos en el periodo de entreguerras (Tesis de doctorado inédita). Doctorado en Historia. Universidad Nacional de La Plata, La Plata, Argentina.

Hora, R. (2014). Historia del turfargentino. Buenos Aires: Siglo Veintiuno Editores.

Karush, M. (2013) Cultura de clase, Radio y Cine en la creación de una Argentina dividida (1920-1946). Buenos Aires: Ariel.

Martocci, F. (2015). La politica cultural del Partido Socialista en el Territorio Nacional de la Pampa: dispositivos y prácticas de intervención de sus dirigentes e intelectuales (1913-1939). Santa Rosa: Universidad Nacional de La Pampa.

Montaldo, G. (2016). Museo del consumo. Archivos de la cultura de masas en Argentina. Buenos Aires: Fondo de Cultura Económica.

Ordaz, L. (1980). Tres comediógrafos sobresalientes. En La historia de la literatura argentina. Buenos Aires: Centro Editor América Latina. 
Pelletieri, O. (2005). Historia del teatro argentino en las provincias. Buenos Aires: Galerna-Instituto Nacional del Teatro.

Sarli, N. (2013). Historia del teatro en el periodo fundacional de La Plata (1890-1930): Identidad urbana y proyecto artístico (Tesis de maestría inédita). Universidad Nacional de La Plata, La Plata, Argentina.

Sarlo, B. (1988). Una modernidad periférica: Buenos Aires 1920 y 1930. Buenos Aires: Ediciones Nueva Visión. 